This is a pre-publication version of a paper forthcoming in Environment \& Planning D: Society and Space. A previous version was published as a working paper at the Centre for Social Science Research at the University of Cape Town. Please refer to the final published version for citation purposes.

Final information will be available at http://kevinpdonovan.com/other-writing/

\title{
Infrastructuring Aid: Materializing Humanitarianism in Northern Kenya
}

Kevin P. Donovan (Anthropology \& History, University of Michigan)

\begin{abstract}
In numerous African countries, humanitarian and development organizations - as well as governments - are expanding expenditures on social protection schemes as a means of poverty alleviation. These initiatives, which typically provide small cash grants to poor households, are often considered particularly agreeable for the simplicity of their administration and the feasibility of their implementation. This paper examines the background work required to deploy social protection in one especially remote area: the margins of postcolonial Kenya. Specifically, it documents the often-overlooked social and technical construction of the infrastructure necessary so that cash transfers may function with the ease and simplicity for which they are commended. Attention to the practice of 'infrastructuring' offers insights into the tensions and politics of what is rapidly become a key form of transnational govermentality in the global South, showing that humanitarian rationalities and subjects cannot be understood independent of the material networks on which they rely.
\end{abstract}

\section{Infrastructures \& Infrastructuring}

Every two months, many thousands of poor Kenyans living in drought-prone areas receive around US $\$ 50$ from British taxpayers. How this money reaches the remote margins of Kenya involves bureaucratic negotiations, political commitment, and ethical ideals. But it also involves rugged trucks, Post-It notes, and carefully washed fingerprints. As these so-called 'cash transfers' become a key form of poverty alleviation in contemporary sub-Saharan Africa, this paper turns away from the high-profile battles over the politics and future of aid and humanitarianism to examine the humdrum and obscure practices that enable actually-existing poverty alleviation. In doing so, I follow Maurer (2012b) to focus on payments infrastructures - "the portals, rails and 
plumbing" - that move monetary value, in this case transferring it from Her Majesty's Treasury to northern Kenya.

A growing body of interdisciplinary literature has turned to large technical systems as both objects of inquiry and objects with which it is good to think. Infrastructure is a multifaceted concept, usually defined as the sociotechnical means through which goods, people, and information circulate; infrastructures incorporate techniques and material objects, not to mention the labor and relations that enable those (Star 1999). In Edwards's (2003: 185) words, "they are the connective tissue and the circulatory systems of modernity." Their absence or breakdown is thus of fundamental importance to the structure of everyday life.

In Larkin's (2013) recent characterization, the anthropology of infrastructure approaches both the "politics and poetics of infrastructure." As means of distribution and "networks of power" (Hughes 1993), infrastructures are "constantly ranking, connecting, and segmenting spaces and people" (Larkin 2004: 292; see also Graham and Marvin 2001). They embody rationalities and politics (Collier 2011) - even if the ability of any one entity to dictate their design is severely limited (Edwards et al. 2007), in part because things themselves display a surprising amount of "recalcitrance" (Bennet 2010) and "intransigence" (Collier 2011). But as cultural anthropologists have emphasized, infrastructures also operate symbolically and aesthetically, stirring the imagination and entwining with ideology (see Larkin 2013: 334-338).

This paper draws on Pipek and Wulf's (2009) concept of 'infrastructuring,' by approaching ethnographically the human and material components of infrastructure in the making.' I draw on fieldwork in Nairobi and the north of Kenya to explicate the types of labor, negotiation, and struggle that enable functional circulatory systems in a region without infrastructural density. In particular, I emphasize the earnest desire of the humanitarian aid 
workers to create functional technologies, embedding them in a novel context, and having them fade into the background; for those infrastructuring, the technology was never the goal— cash assistance was - but enabling the circulation of monetary value required considerable attention to infrastructure.

The importance of infrastructuring as a concept is both empirical and normative. Despite recent attention to what has come to be known as the process philosophies of Whitehead, Deleuze, and Latour, discussions of materiality too often lapse into a certain assumption of static physicality. 'Infrastructuring' helps to avoid that, demanding an attention to the ongoing negotiation at moments of both creation and breakdown (see Jackson 2014; Graham \& Thrift 2007). It unsettles the ontological assumptions of fixity and demands studies in situ in order to capture the ongoing maintanence, preservation, extension, and decay of sociotechnical systems. And as the following makes clear, it also reworks political assumptions about infrastructures and other technologies of power, avoiding assumptions about their dominance.

Moreover, a study of infrastructuring aid adopts and reworks the rich critical literature on humanitarianism, human rights, and development. In doing so, it parts from an idealist attention to politics, law, and ethics to focus on the importance of mundane matters. As Fassin (2007b) has argued, universal humanitarian ideals are in practice founded on differences and hierarchies: "the noble goals of... saving endangered others and alleviating suffering everywhere in an indiscriminate manner" contradict the "concrete terms under which humanitarian agents have to operate".

My contention is that the recalcitrance and intransigence of humble things - and their articulation with political rationalities and modes of subjectification - has much to do with the ways in which abstract universals become lived inequalities. Because global humanitarian 
biopolitics requires infrastructuring, it manifests in divergent and negotiated ways - ways that are not reducible to the humanitarian actors or logics alone. Thus, the following sections highlight the particularities of cash transfers in northern Kenya before turning, in the final section of this paper, to a more sustained engagement with what it reveals about the biopolitics of humanitarianism.

\section{Gash Transfers}

The history of humanitarian and development interventions in Kenya is, of course, mottled, driven in part by a volatile mix of donors, politicians, bureaucrats, and recipients. In recent years, the government and major donors such as the World Bank and the UK's Department for International Development (DfID) have begun to invest in "social protection" schemes known as cash transfers. This method of aid has grown dramatically: a survey conducted in 2009 found 123 cash transfer programs in sub-Saharan Africa (Garcia and Moore 2012). These initiatives provide small to medium cash grants to poor and vulnerable populations, with some requiring that specific conditions are met (such as school enrolment or vaccination for children), while others are unconditional. As leading proponents enthusiastically sum up, the mantra is "just give money to the poor" (Hanlon et al. 2010).

The genealogy of these forms of aid is mixed. In some cases - such as South Africa (and some surrounding countries) - they "reflect... a classic 'northern' conception of desert" (Seekings 2008: 33) which provide socialized assistance to those populations unable to meet their own needs (e.g. the elderly, the infirm, and children). As Ferguson (2010) points out, in places like Kenya the precursor is more often emergency food aid than welfare, with humanitarian organizations promoting cash instead of calories. But as I discuss below, while humanitarian in origin, program 
officials have aspirations for institutionalizing cash transfers as rights-based social welfare, and these aspirations are directly influencing their infrastructural design in the present.

In Kenya, there are two major cash transfer programs, each operated and funded by a mix of government, donors, NGOs, and even private industry. From 2005 to 2010, spending on social protection grew from KSh 33.4 billion to 57.1 billion (from about US $\$ 367$ million to $\$ 628$ million), equivalent to 2.28 percent of GDP (GoK 2012). ${ }^{1}$ The two major programs are the Orphan and Vulnerable Childen (OVG) program and the Hunger Safety Net Program (HSNP). The OVG program provides KSh 2,000 (US \$22) to 412,470 beneficiaries every two months. The HSNP - discussed in this paper - is targeted at "chronically food-insecure, extremely poor, and vulnerable people" in the arid and semi-arid lands, largely in the north of Kenya.

The appeals of cash transfers are multiple. A decades-old critique of food aid, most prominently espoused by Amartya Sen and Jean Dreze (1991), has recently become more broadly acknowledged: importing foodstuffs tends to undermine local farmers, leading to long-term decay in productive capacity. Furthermore, advocates of cash transfers argue that aid beneficiaries often need assets beyond food. Cash, as a fungible medium of exchange and durable store of value, offers a more permissive type of aid, not likely to spoil like food.

Finally, proponents of cash transfers suggest that they are a more feasible form of aid, less likely to result in failure. For example, Samson et al. (2011) write that "In many ways, cash transfers require less government bureaucracy and administrative resources than other mechanisms for social delivery." They are "administratively feasible and affordable". Importantly, technology is key to this vision. Hanlon et al. (2010: 145) say "[n]ew technology is transforming the administration of cash transfers, making it practical in even the poorest

\footnotetext{
${ }^{1}$ At the time of my fieldwork, the Kenyan Shilling was worth approximately .011 US Dollars. I provide approximate conversions where applicable.
} 
countries" and the World Bank reports that early signs suggest "new leapfrog technologies" including biometric identification can "overcome challenges that are relatively unique" to subSaharan Africa (Garcia and Moore 2012: 7).

Similar arguments appeared throughout my fieldwork, such as the recognition that cash was more feasible and affordable than food: one program manager told me "a bag of 90kg maize would cost, like, over KSh 10,000 [\$110] for it to be transported from Mombasa to [Turkana in the north]. Then, if perhaps [a beneficiary] is supposed to get a 2 kilogram container of maize, he may end up getting 500 grams because the rest has [disappeared]."2 Others believed that "technology has been a great enabler to create an efficient institution" capable of delivering grants in rural areas. ${ }^{3}$

Despite this general consensus, the ability to deliver cash to the vulnerable and poor populations in Kenya still requires a considerable investment in institutional and infrastructural innovation. Perhaps no one recognizes this as much as those members of government, industry, and civil society that manage the Hunger Safety Net Program (HSNP). Since 2008, HSNP has provided cash transfers in the arid and semi-arid lands of Kenya. According to some estimates, by 2012, the program reached nearly 400,000 beneficiaries in the historically drought-prone and impoverished counties of Mandera, Wajir, Marsabit, and Turkana. Where I conducted my fieldwork in and around the capital of Turkana - Lodwar - is indicative of the region, with more than 90 percent of the population below the poverty line, many of who are engaged in pastoral livelihoods dependent upon weather (GoK 2012). ${ }^{4}$

\footnotetext{
2 Informant \#12, an HSNP official (March 2013).

${ }^{3}$ Informant \#2, a financial technology practitioner involved with HSNP (March 2013).

${ }^{4}$ For Turkana, see McCabe (2004).
} 
HSNP is a partnership with the government of Kenya, funded largely by the UK's Department for International Development (DfID), and with various non-profit humanitarian organizations such as Oxfam, World Vision, Save the Children, and HelpAge International managing components. Importantly, payments are managed by one of Kenya's largest private financial service providers, Equity Bank, selected for its ability to manage such a volume of cash dispersals and having existing access to payments technology. ${ }^{5}$ At the start of the HSNP, qualifying households received KSh 2,150 every two months (\$24), but due to inflation and drought, it has incrementally been raised to KSh 4,600. Due to positive assessments, the governments and donors have agreed to continue and expand the program, a process I witnessed during fieldwork.

\section{Of Banks, Biometrics \& Barazas: Establishing Payments Infrastructure in Northern Kenya}

"We have issues, much issues. From training to hardware." - Informant \#10, an OVC official (March 2013).

Enabling the circulation of aid workers, money, and recipient identities in northern Kenya is not straightforward. Even within Kenya's social protection sector there are a variety of means of payment. Consider the Orphan and Vulnerable Children (OVG) program that reaches more than 400,000 beneficiaries as of 2010. The OVG has traditionally relied on the parastatal Postal Corporation of Kenya (PCK) to dispense physical cash at its network of 471 branches. To identify recipients, the staff in Nairobi prints in triplicate the names of beneficiaries. A copy is transported

\footnotetext{
${ }^{5}$ In this way, it reflects aid's "multi-level and increasingly non-territorial decision-making networks that bring together governments, international agencies, non-governmental organizations" (Duffield 2001: 11) and, I might add, corporations.
} 
by vehicle to each PCK branch where recipients queue on appointed days, present their identity card, and either sign or provide an ink fingerprint to acknowledge receipt. From the beginning to successfully distributing the printed payrolls can take two weeks alone. As one OVG official told me, gesturing to bookcases overflowing with reams of paperwork, "all those bureaus, it's a lot of work... it's hard work." The unwieldy paper books are then returned and stored at the OVC headquarters. There, "our finance guy," as he was known, "has to look through all those papers to reconcile."6 This tedious process of data entry eventually results in a digital record of who has (supposedly) been paid and who has not.

Numerous social protection professionals described the system as archaic and uncertain. The PCK lacks up-to-date technology such as access to the national payment system or digital cash registers. Because financial reconciliation occurs manually, I heard frequent worries about the potential for fraud and leakage: "You see, with the manual payroll, somebody can take your ID, present himself or herself with the PCK, and get the money."7 Despite these worries, the partnership with the PCK was considered a marked improvement upon a previous iteration that relied on local chiefs in rural areas to distribute envelopes of cash - a practice believed to be marked by bias and patronage. And although both the head of the OVG and a World Bank representative suggested they were decently assured of the current system's reliability, the potential of fraud had motivated a shift toward an electronic payments infrastructure that used biometric fingerprinting to identify recipients. "With the biometric enrolment," I was told, "it's only your fingerprints, your 'bios', that can access your money."8

\footnotetext{
${ }^{6}$ Informant \#10, an OVG official (March 2013).

7 Informant \#10.

${ }^{8}$ Informant \#10.
} 
Electronic payments that used biometric authentication are at the core of the Hunger Safety Net Program, as well. When HSNP was inaugurated in 2008, the OVG system of paperwork, identity cards, and the Postal Corporation was deemed infeasible. At one level, the reason is straightforward: the PCK is not meaningfully present in the arid and semi-arid lands. As one of the program's designers frankly told me, "pastoralists don't receive mail."9 There were 17 PCK branches in the entirety of the four HSNP counties, an area of more than 220,000 square kilometers. Of these, many were not connected to a mobile network and in poor physical condition. Concentrating payments in these locations would not only be inconvenient for recipients, it could mark the locations as prime targets for criminals due to the volume of cash.

How to proceed without the PGK, though, was less clear, so the HSNP pioneered a new payments infrastructure with two key innovations: biometric identification and banking agents. In this system, recipients' fingerprints are scanned at enrolment and then used to identify them when they travel to local shopkeepers who were appointed as HSNP payment agents. The next three sections detail the efforts to create a functional payments infrastructure through particular attention to identification, enrolment, and payment agents.

\section{Identification}

"[Beneficiaries are] illiterate and we felt that it would be difficult to obtain signatures or for them to remember PIN numbers etcetera." - Informant \#3, an NGO official coordinating HSNP payments (March 2013).

\footnotetext{
${ }_{9}^{9}$ Informant \#3, an NGO official coordinating HSNP payments (March 2013).
} 
In recent years, aid programs have become the subject of increasing audit imperatives, encouraging meaningful changes in everyday practice. ${ }^{10}$ In the case of cash transfers in Kenya, one of the chief means of accountability is the creation of identification regimes that seek to block fraud, dissimulation, and errant payments. ${ }^{11}$ Identification is important at two crucial interactions: enrolment into the HSNP when personal information is gathered and at payment when eligible individuals receive their grant.

However, governments in both colonial and post-colonial Africa have historically invested little in such identification schemes (Szreter and Breckenridge 2012), and in Kenya many lack reliable identification documents. Because births often go undocumented, the 'documentary chain' is never started, thus making it more difficult to acquire documents later (Setel et al. 2007). ${ }^{12}$

Around 2008, when Phase I of HSNP began, reportedly 15-20 percent of adults in the program areas lacked national IDs. For those that did have an ID, it was often tattered, damaged, or out of date. Negotiating the bureaucracy to acquire an ID was difficult, could take up to a month or more, and would incur a KSh 100 fee (or KSh 300 for a replacement). Women may not have IDs because their husbands managed bureaucratic affairs, but given the more general lack of need for identity cards, many Turkana simply did without. As one program officer told me, "no one is going to stop you in the middle of the desert and ask where is your ID." Yet, for both programmatic accountability and because of so-called 'know your customer' financial regulations, identification of beneficiaries was crucial to HSNP.

\footnotetext{
${ }^{10}$ See Mosse (2004), Rottenburg (2009), and Jensen \& Wintheriek (2013). On audit generally, see Power (1997).

${ }^{11}$ For a similar audit imperative and biometric response in South Africa, see Donovan (2015).

${ }^{12}$ In such cases, community elders are asked to vouch for the veracity of undocumented individuals' claims to Kenyan birth.
} 
HSNP reacted to the challenge of identification at enrolment and payment in two manners. One of the partner organizations, HelpAge International, was responsible for advocating locally on behalf of those without identity cards. Their effort was assisted in the leadup to the national election in early 2013 where ID cards were made free and registration promoted through a "huge push" in order to boost voting. ${ }^{13}$ By 2013, the situation had thus changed, with far more Turkana having the national ID that was required to enroll in HSNP. In addition to enabling receipt of the cash transfers, some people told me that acquiring an ID removed local forms of dependency for those who previously relied on ID-wielding third parties to act on their behalf. ${ }^{14}$

While a national ID was a key component of HSNP enrolment, payment required a means of authenticating identity that was considered suitably secure and reliable. Identity cards were not likely to last long enough, it was felt, or may also lead to forms of dissimulation such as using another person's card. Thus, during enrolment, HSNP collected digital fingerprint scans of beneficiaries that were then used to verify individuals before each payment. As a major donor official related, "I think as institutions and as a government, there has to be a case for secure payments. We need to provide a reasonable level of assurance that the right people are being paid the right amounts, in the right time, in a secure fashion. And I think for us and some of our partners... the push has generally been for biometrics and for electronic payments because, at the moment, those are some of the most secure, to our minds' knowledge, means of paying beneficiaries." 15

\footnotetext{
${ }^{13}$ Informant \#2, a financial technology practitioner involved with HSNP (March 2013).

${ }^{14}$ Informant \#3, an NGO official coordinating HSNP payments (March 2013).

15 Informant \#8.
} 
Adopting biometric identification, however, is not without its downsides. For one, digital fingerprinting is a relatively untested technology, prone to failure (Magnet 2011), especially in places like northern Kenya. It tends to be expensive: the biometric authentication device costs around KSh 50,000 (\$550) and the cost per transfer is nearly double some alternatives. Biometric payments infrastructure is also proprietary, meaning it does not interoperate with normal ATMs, shops' devices, and the like.

Instead of biometrics, HSNP could have adopted personal identification numbers (PINs), like those used in debit cards around the world. PINs are standard, well tested, and considerably less expensive, yet they were rejected for reasons that reveal much about the rationalities operating within this particular humanitarian intervention.

There were two key attributes of biometric identification that HSNP officials found compelling in their quest for "a reasonable level of assurance". First, it individualizes identification because of the presumed uniqueness of each person's fingerprints. Individualizing cash payments was important for HSNP officials who spend considerable time and effort determining who qualifies for support. Program administrators were concerned that sharing PINs would enable others - whether wayward family members or unscrupulous shopkeepers - to defraud beneficiaries, thus undermining the program's goals.

The second reason for rejecting PINs was considered more important. Almost universally, when I would ask why not use PIN authentication in the HSNP, I was told it was because recipients were "illiterate." "Even writing down a PIN and keeping it secure," I was told, "can be a challenge for pastoralists" who lack "desks or drawers or anywhere where they can keep some of 
these documents." ${ }^{16}$ Biometric identification, on the other hand, absolves the need to remember a PIN by affixing the means of identification to the material body (van der Ploeg 2005); it was thought, then, that it would remove the need for elderly beneficiaries to rely on a PIN-savvy assistant. HSNP recipients cannot, as one person put it, "forget their thumb." 17 Thus, it was quite explicitly a particular understanding of the intellectual (in)capacity and material culture (or lack thereof) that informed the adoption of biometric identification by HSNP.

Neither conception is prime facie wrong - and at least some HSNP recipients did prefer to not remember a PIN; yet, the belief that illiteracy prohibits PIN authentication is curious. For one, remembering a four or five digit number would not seem to be a matter of literacy; it should not even be a matter of numeracy, as it does not require any math. Secondly, Kenya is now well known for the success of mobile money services like M-Pesa, including amongst poor and illiterate populations (Maurer 2012a). More than 15 million M-Pesa users manage to use a PIN for each transaction. A more accurate consideration would rather note that HSNP cards are used less frequently than mobile money accounts, thus heightening the chance of forgetting a randomly assigned string of numbers. Furthermore, due to technical reasons set by distant financial corporations, resetting a forgotten PIN is a difficult and time-consuming endeavor in rural areas due to the requirement to re-issue a new physical card along with a new PIN.

Affixing identification to the material body, however, caused complications. HSNP needed to allow beneficiaries to nominate a secondary recipient whose fingerprints would also be accepted for payment. This was because some beneficiaries are unable to travel to payment agents and because apparently around one percent of beneficiaries are consistently unable to use

\footnotetext{
16 Informant \#3. Some individuals kept documents around their neck in pouches akin to a tourist's passport holder.

${ }^{17}$ Informant \#3, an NGO official coordinating HSNP payments (March 2013).
} 
biometrics due to damage to their fingerprints (such as from age, manual labor, and smoking). Additionally, over time fingerprints reportedly became damaged, such as through a game that the Turkana people play in the sand. ${ }^{18}$ Even this small percentage has proven "a fairly big problem" according to one donor official, and those in charge of handling HSNP complaints and grievances told me that the "majority of the complaints we receive through the grievance system is because people can't access their money through the card because of the fingerprints." 19 To overcome this type of exclusion, HSNP permitted a secondary recipient to be registered, oftentimes a family member who would withdraw cash for the actual recipient. As I was told, "On humanitarian grounds, even one exclusion is too much." ${ }^{20}$ The dual recipient structure of HSNP did permit some form of access to those unable to use biometrics, but it also introduced a form of dependency, with some reported cases of the secondary recipient taking advantage of their dependent.

For humanitarian organizations there are at least three ways that adopting biometric technology "scripts" reality, to use Akrich's (1992) term for how materiality makes hypotheses about the world. It assumes mobility because it requires the person to be present for its use (unlike a PIN which can be shared). ${ }^{21}$ It assumes corporeal stability through its failure to recognize that fingers deteriorate (with age and through temporary abrasions). And it assumes uniformity by assuming all people are equally able to provide fingerprints even though a meaningful proportion is incapable of doing so (cf. Lyon 2003). The standards that infrastructures embody allow action at a distance, but this is not always equal access, troubling the humanitarian ethos of "even one exclusion [being] too much.”

\footnotetext{
${ }^{18}$ Informant \#12, a Turkana-based financial services coordinator for HSNP (March 2013).

${ }^{19}$ Informant \#5, an NGO employee involved with HSNP (March 2013).

${ }^{20}$ Informant \#14, a Turkana-based NGO employee coordinating HSNP (March 2013).

${ }^{21}$ On the potential desirability of this in a similar context, see Mas (2012).
} 
Further difficulties of mutual orientation between users and infrastructure are illustrated by the case of enrolment in biometric identification. In addition to its individualizing capacity, fingerprinting has been favored because of its presumed universality; unlike 'literacy' or the capacity to remember a PIN, everyone can present their finger, HSNP's designers reasoned (cf. Foucault 2009). Equity Bank's director of technology told me that "some of the people targeted are not numerate or sometimes you can be illiterate. And the biometric removes that indignity of having someone carrying a PIN because everybody is able to be served... it's all part of the dignity thing." 22

But achieving universality is less straightforward than often assumed. In some cases, would-be beneficiaries were suspicious of biometric technology (not to mention the novel idea of free money). Within the ethnic Somali population in northeast Kenya this was prompted by worries that HSNP was "capturing these details to share with the Americans" or "convert them to Christians". ${ }^{23}$ In other instances people worried that the information would be shared with the police for criminal investigations. ${ }^{24}$ These admittedly rare instances of hesitation were usually overcome through a process of "sensitization" - as the HSNP officials called it. Through convening barazas (Kiswahili for community gathering), HSNP representatives explained the program and the technology. Here, they particularly valued the support of chiefs in gaining the public's acceptance, demonstrating the need for infrastructure to rely on interpersonal trust and authority, as well as technical efficacy.

\footnotetext{
22 Informant \#2, a financial technology practitioner involved with HSNP (March 2013).

${ }^{23}$ Informant \#11, an NGO employee and HSNP partner (March 2013).

${ }^{24}$ Informants \#3 and 11, two NGO employees working with HSNP (March 2013).
} 


\section{Enrolment}

This social act of building goodwill and trust was followed by enrolment, during which the technology proved far more intransigent than the beneficiaries. The international humanitarian organization Oxfam largely conducted enrolment and allowed me to observe their work in 2013 when they were registering beneficiaries for HSNP's expanded Phase II. This was an enormous task, involving traveling more than 400 kilometers in some cases to register more than 99,000 households (or more than 600,000 individuals). Registering one individual could take more than 10 minutes in some cases. Because of the risk of future drought, HSNP hoped to register all residents to enable rapid expansion in the future. "The idea," I was told, "is to have a database so that when we do have some element of an emergency, some sort of shock, we don't have to start going in to register everybody from scratch." ${ }^{25}$ In this way, expectations of the future crises were being embedded in the present-day act of infrastructuring.

To do so, they used teams of mobile registrars composed of young Oxfam employees from the region. Although they did not share the dress or livelihood of the largely pastoral communities they enrolled, these aid workers did know the local language and have a better understanding of local practices and customs. Given the vastness of Turkana, the shoddy transportation infrastructure, and the time it takes to enroll beneficiaries, it was impossible for the teams to return to the county capital of Lodwar each night. Instead, they operated on twenty-day shifts, camping near the villages they were registering. In one case I observed, they had set up their tents inside unused classrooms and were thankful for the only concrete buildings when an unseasonable rainstorm swept through.

25 Informant \#5, the HSNP lead for a partner NGO (March 2013). 
These aid workers were active infrastructurers, building the means through which cash could ultimately circulate. But in doing so, they relied on existing infrastructure like the school buildings or rugged SUVs. As with the Médecins sans Frontières teams that Redfield (2013) documented, Oxfam relied on Toyota Land Cruisers, ubiquitous within humanitarian work, to traverse extended distances through which there were no paved roads. ${ }^{26}$ These vehicles are rugged enough to be quasi-independent of roads and also standardized enough to be easy to repair. It is hard to imagine establishing a cash transfer in remote Turkana without them, but while SUVs permit humanitarianism where roads are lacking, they are also a structuring, hierarchal agent. One of the everyday realities of Turkana is contending with fragmented, decrepit infrastructure (cf. Larkin 2008) but the functionality of the Land Cruiser allows those with access to move about more fluidly. As Smirl and Lister (2010) argue, being in a car produces an affect of speed, placelessness, and separation. It positions the aid worker (or visiting ethnographer) as more secure- even more dangerous - as the vehicle hurdles though the bush where goats and their young herders roam. Infrastructured space is manageable space (Dourish and Bell 2007), but only for those with access to the infrastructure.

Because Land Cruisers are so reliable, the aid workers rarely considered them. More central to their concern was the information technology used to build the administrative and payment systems for the HSNP. While some worked smoothly-fading into the background as functioning infrastructure - others were deeply problematic. For example, from the end of 2012 to early 2013, the fingerprint scanners used to enroll beneficiaries repeatedly failed. For subsequent authentication, it is important that the initial biometric scan is of high quality, but the finely tuned scanners succumbed to a range of maladies. Dust and heat proved particularly fatal,

${ }^{26}$ Given the incapacity to repair paved roads in Turkana, dirt paths were actually preferred to once-paved roads, now riddled with potholes - except when it rains. 
and in January 2013 the failures had become so frequent and the delays so onerous that they had simply stopped registering fingerprints, and no one quite knew how they were going to fix the situation. Nor did they know what exactly caused the failures: while dust and heat were blamed, the complexities of the biometric devices, and the fact that they were bought from a foreign firm, meant no one in Nairobi - let alone Turkana - had the wherewithal to diagnose or solve the infrastructural breakdown.

Similar frustrations in the process of infrastructuring cash transfers arose from the computer software used to collect the personal details of the HSNP beneficiaries. In order to accurately pay the neediest, HSNP had developed a model known as the 'proxy means test' (PMT) that determines need and desert through an assessment of the number of dependencies, access to resources, and more. As one HSNP employee told me, the PMT algorithm makes calculable and commensurable "differences in socioeconomic [status]... because some people farm, some people fish, some people herd cattle. How do you come up with some sort of balance where you can say this person farms here is just as poor as this person who does fishing there?" The PMT was the means of doing so, but it, too, was trouble.

By April 2013, the software that managed the PMT was already on version 10.1. Each update represented a bug, error, or incongruence that necessitated a lengthy process of receiving an update from Nairobi that had to be transported the last distance on physical flash drives because telecommunications were too sparse. ${ }^{27}$ At times, this was a significant delay: from August

\footnotetext{
27 The situation was even worse for the Orphan and Vulnerable Children program whose software was (for reasons unclear) developed and managed by a team in Colombia. As I was told, "every time you want to modify or make an upgrade, you have to go back to the developers, some firm in Colombia... It's amazing how difficult it is then just because the system, because you know, it affects everything. It affects payments, complaints and grievances; it affects everything. So the system has not been able to lodge complaints for instance. You know, you want to check the system to see, does it have the functionality to
} 
to December work stalled due to a software glitch. For example, the software's designers had assumed monogamy in their survey although polygamy was not uncommon amongst the Turkana. Similarly, it would not permit a 65-year-old man to be listed as the father of a threeyear-old son, though this, too, occurred..$^{28}$

The Oxfam staff struggled against these meaningful tensions, attempting workarounds and tweaks. As active infrastructurers, they opportunistically relied on existing resources where possible. Because their computers would overheat in the mid-day sun, they worked in a thatch hut that was previously used to deposit food aid but had to reposition every few hours as the sun moved, blinding their camera used to take ID pictures. At the same time, a small solar panel enrolled and converted the sun into an ally that powered their computers.

Throughout this, they needed to negotiate with the local populations, providing ad hoc solutions to their needs, such as allowing registration exceptions for women who needed to tend to their crops. Some beneficiaries were exasperated by the tedium of providing so much information. "If you're here to help," they told Oxfam, "just help." At times, beneficiaries subverted the plans of the HSNP representatives, leading to a sort of quiet contest as to who would control the emergence of the aid infrastructure. For example, as a result of the proxy means test, beneficiaries were assigned to one of four income brackets (very low, low, middle, and high). The aid workers had previously used an informal system of colored stickers on ID cards, with pink corresponding to very low, yellow to low, and so on. Although this was never disclosed to the grant recipients, they evidently recognized the pattern and soon enough Oxfam noticed that cards had been reshuffled, in contradiction to the dictates of the proxy means test. The quick

be able to do this? Well we need to go back to the developers in Colombia. Number one because they know their system. Even if they knew the system locally, it's in Spanish."

${ }^{28}$ Informant \#5, the HSNP lead for a partner NGO (March 2013). 
fix that they adopted was to discard color-coding and instead use letters, with 'TCW' indicating 'Turkana Central Wealthy. Literacy, then, became a tactic in infrastructural contests.

\section{Agents}

After biometric identification, the second crucial means of infrastructuring cash transfers in northern Kenya was the system of agency banking, a practice of appointing local shopkeepers as cash dispersal entities. In early 2013, there were 52 Equity Bank-appointed agents in Turkana who served as the frontline of this humanitarian intervention. HSNP agents are small businessowners - often little more than a stall with some packaged food and drink - that verify beneficiaries by inserting their HSNP card and scanning their fingerprints on a specialized device. If the finger's ridges match the image on the card, then the agent hands over the cash with which the beneficiary is free to do as he or she pleases. As with a proliferating range of "humanitarian goods" (Redfield 2012), the use of agents highlights the curious mix of public, private, and civil society actors who now constitute humanitarianism, an enormous global enterprise that Fassin (2007a) characterizes as "nongovernmental government."

This model of incorporating local shopkeepers was pioneered for at least three direct reasons. First, by delegating responsibility to already existing entities, it reduces the upfront cost of deploying a payments infrastructure. HSNP does not need to establish facilities de novo. Because formal businesses are confined to the few population centers in Turkana, informal shops were the only existing infrastructure on which to build. Even today, "In the rural, the remote location, there is only the Equity agent." ${ }^{\prime 29}$ If HSNP reflects a growing form of transnational governmentality (Ferguson and Gupta 2002), the street-level bureaucrats of tomorrow are likely to be private shopkeepers or NGO officials, not civil servants (cf. Lipsky 1980).

\footnotetext{
${ }^{29}$ Informant \#3, an NGO official coordinating HSNP payments (March 2013).
} 
Second, because agents are responsible for cash management, it limits the ongoing administrative burden to HSNP. On average, for every 1000-2000 beneficiaries, 4 to 5 agents are needed, each distributing millions of Kenyan shillings in the course of a payment cycle. This, in turn, permits a longer payments window that reduces waiting time and inconvenience. Finally, the combination of lower costs enables a much larger network of payment points to be established, assisting their goal of having an agent within 7 kilometers of all recipients. ${ }^{30}$

At HSNP's inauguration, regulations from the Central Bank of Kenya did not allow nonbanks to provide financial services. Such a rule is common in the prudential world of financial regulators, and required Equity Bank to acquire a special exemption to deputize would-be agents. Today, though, agency banking has grown enormously in Kenya and elsewhere through its use in mobile money, where agents are sometimes referred to as "human ATMs" (Maurer et al. 2013). This phrase is revealing for distilling what is the core purpose of the agents: cash provision. As with Latour's (1994) discussion of 'gunman' it also reveals the interlacing of both human and machine in the provision of cash. That is, the union of shopkeeper and biometric device is what allows this infrastructure to function.

For a range of reasons, a purely automated teller machine would not be feasible in Turkana where the necessary supporting infrastructures are absent. First, HSNP agents are responsible for acquiring the necessary cash to pay beneficiaries. Because bank branches are scant, this can involve considerable travel, but the shopkeepers already have the need and means to acquire cash for their businesses. Additionally, because serving as an agent implies a significant amount of new customers, the agents have a clear incentive to gather cash from afar. In programs that do not use

\footnotetext{
${ }^{30}$ It is perhaps worth emphasizing that despite this capillary form of distribution, HSNP beneficiaries still need to be highly mobile to reach the agents. Although some HSNP officials were of the opinion that 7 kilometers is normal for pastoralists, others noted that if something went awry at the agent (such as a biometric device failure), it was a long distance there and back for naught.
} 
agents - such as the OVC-I was told that centralized cash management is "a nightmare" requiring armored trucks, insurance, and logistics. ${ }^{31}$ Delegating the requirement onto properly incentivized agents removes this difficulty from the social protection program. Additionally, electricity is at best unreliable but more likely altogether absent. To surmount this challenge, payment devices are battery powered and recharged through solar panels that Equity provides on credit to the agents. HSNP's payment devices also function with intermittent telecommunications infrastructure: balancing and reconciling the accounts can occur whenever the agent is able to travel to a location with network coverage. This was necessary because at the beginning only 40 percent of Turkana had mobile network coverage. ${ }^{32}$

In addition to using agents to cope with infrastructural deficits, HSNP actively sought certain social, cultural, and interpersonal characteristics from their 'human ATMs'. Chief amongst these is trustworthiness: Equity does due diligence to ensure they are not selecting anyone nefarious, combing what formal records exist and querying the local community about the character of a would-be agent. Although the agents' profit interest is crucial to their enrolment, HSNP officials expressed a desire to avoid agents who were driven only by such a motivation.

They also need people with compassion and understanding of the needs of the recipients that a machine would be incapable of providing. As the head of Equity in Turkana told me, "We wanted an agent who would be a bit humane, treat them with dignity and be able to humble

\footnotetext{
31 Informant \#15, a payments consultant for OVG (March 2013).

32 Although it has improved, mobile coverage is still limited, so HSNP is moving toward satellite connections in order to improve the real-time connection to agents. In part, this is motivated by financial regulations - written without Turkana in mind - that require real-time reconciliation for providers of fullservice finance (a goal of Equity Bank for its currently special-purpose agents).
} 
himself." 33 As such, they provide training to convey the humanitarian ethos of HSNP and the goals of the service. For example, entering the formal Equity Bank branch in Turkana can be intimidating: the whir of a generator, sleek marble facades, glass partitions, and the bevy of technologies clearly set the space off from the rest of the locality (cf. Augé 2009). A shopkeeper from the community is far more approachable.

The method has proven largely successful, with few complaints, even though there is the potential for agents to take advantage of the grant recipients. Only in one case was impropriety found to be occurring: when the grant was valued at KSh 2,250, a couple of agents began dropping the last KSh 250 (\$3) because of the difficulty providing such small denominations in such volume; instead, they offered free goods from their shop valued around KSh 250. When Equity learned of this, they disciplined or dropped the offending agents, explaining that "the [human] rights component is always there to check any malpractice and what have you." 34 In this case, it was the pragmatics of actually existing money (the denominations and difficulty of creating change) and the presence of commercial actors that shaped behavior; it was a regulative ideal of rights-based humanitarianism that corrected it. ${ }^{35}$

Agents are particularly interesting because they exhibit elements of both black-boxed technology and skillful humans. On the one hand, HSNP desires cash distributors who are objective, delivering money without inappropriate behavior such as fraud or theft. As one Equity official told me, the ideal agent is "somebody who will practice what we say." 36 On the other hand, they want subjectivity, the sort of human touch that will assist with troubles when they

\footnotetext{
33 Informant \#12, a Turkana-based financial coordinator for HSNP (March 2013).

34 Informant \#12.

${ }^{35}$ On the pragmatics of money, see Guyer (2004). I thank Taylor Nelms for his comments on this point.

36 Informant \#12.
} 
arise ${ }^{37}$ Of five payments I witnessed occurring, two of the fingerprint authentications originally failed; they succeeded only through the assistance of the payment agent who scrubbed the finger clean and placed it on the device correctly, cajoling human and machine to successfully interact (cf. Suchman 2006).

Agents - in addition to other arts of infrastructuring discussed here - can be understood as means of 'embedding' foreign practices into Turkana. As Takhteyev (2012) has discussed, moving a sociotechnical practice requires practical work, tacit knowledge, and technical accomodation to first disembed it from a previous context and then re-embded it in a new one.

Arguably this process of embedding infrastructure is made more difficult by the paucity of existing resources on which to build. Even where there was an "installed base" (Star 1999) (such as shopkeepers), rules needed to be changed to permit their use as financial intermediaries. Far more common was the case of biometric identification: a technology novel in most of the world, let alone Turkana. The act of embedding it within the Turkana context required endless maneuvering, each with their own set of supporting practices. Solar panels could power the biometric devices at agents, but required extending credit to shopkeepers who could not purchase them outright. Tablet computers could acquire the necessary administrative data in bulk but required shade during the day and software updates to be carried to the field by flash drive. Identity cards could be acquired, but needed the cooperation of local bureaucrats as well as pockets in which to keep them. Pull a single strand of the cash transfer infrastructural web and who knows how far it will go, yet given enough infrastructuring, circulation can occur, as cash does with a high degree of success in the Hunger Safety Net Program.

\footnotetext{
37 The goal is transmission, but recognizing that certain transformations will be needed in order to do so; in the words of actor-network theory, 'intermediation' requires some 'mediation' (Callon 1986; Latour 1999). On objectivity more generally, see Daston \& Galison (2007).
} 


\section{The Biopolitics of Infrastructuring Aid}

Cash transfers have risen to prominence within the humanitarian aid industry as a feasible means to alleviate poverty, reduce vulnerability, and meet other goals such as boosting health and education. The logic follows a view of the poor as rational actors and markets as a means to effectively meet their needs (see Ferguson 2010). Recent studies have emphasized the biopolitical aspect of humanitarianism, and in their effort to foster life, cash transfers follow a broadly biopolitical logic of transforming zoê into bios. In Fassin's (2009) influential conceptualization, human bodies have become the animating authority of political legitimacy. His concept of "biolegitimacy" emphasizes the elevation of biological life to its contemporary position as an ultimate political value, while simultaneously showing the ambivalent results of this humanitarian politics. For many, this involves a refusal of the political (e.g., Ticktin 2011) and seeks to manage surplus populations and their risks to the hegemonic order (e.g., Duffield 2007). Yet the analysis here follows a conviction that biopolitics is less a global diagnosis than an analytic orientation. As Stephen Collier (2011: 17) writes, "There is no underlying "logic" of biopolitics but different ways in which the government of living beings is made a problem of reflection and intervention" (see also Rabinow and Rose 2006).

In the case of the HSNP, humanitarian rationalities and modalities of subject-formation were always articulated with the materiality of the intervention. Constructing "zones of political entitlements and claims" (Ong 2006) involves everyday engineering. The infrastructure of humanitarianism - indeed, humanitarianism itself - is an incomplete, heterogeneous assemblage, prone to failure and in need of constant maintenance and repair. Insofar as humanitarianism exhibits its political effects, it is because of the ongoing labor - technical, political, and otherwise. The processual, particularizing approach taken in this study follows from a commitment to not 
presume a priori that some actors are more powerful than others, but rather to study how "a difference in relative size is obtained" (Callon and Latour 1981). Humanitarian workers can and do wield considerable power - in this case and others - but they do so by building and maintaining sociotechnical networks.

For those creating the HSNP infrastructure, programmatic rationalities and logics were often in friction with sociotechnical systems. As detailed above, the demands for securitized accountability compelled the adoption of biometric identification. In turn, the technological scripts created exclusions, failures, and new forms of dependency which challenged the inclusionary ethos of the HSNP. At other times, the shift from food to cash induced new material pragmatics that, when confronted with shopkeepers' constrained time and profit motive, again challenged certain HSNP rationalities - namely, that everyone receive the full grant. Infrastructuring reveals the internal contradictions of particular aid projects.

To understand the "aporia" of humanitarianism - the way in which abstract universals become practical inequalities (Fassin 2007b) - requires attention to the particularities of infrastructuring aid. The distributed networks of contemporary governmentality are not only negotiated by individuals in places like London or Nairobi, they are also enacted through sociotechnical negotiations on the ground while infrastructuring. As such, there is no clear sovereign voice, no absolute decision about the state of exception (on this generally, see Brown 2010).

Undoubtedly, humanitarianism functions in part through a permanent state of emergency, an exceptionality that challenges existing laws, constraints, and limits (Duffield 2007). A sense of urgency curtailed more fundamental questions about history and political economy in Turkana. Rendered as such, HSNP facilitated the adoption of a technology once considered 
exceptional and now increasingly normalized: as with other surveillance techniques, the use of biometric identification is usually first justified first for criminals, non-citizens, the poor, or other threats to public order, and overtime they become normalized (see Ajana 2013). Concerns over the privacy implications of biometrically enrolling HSNP beneficiaries were therefore downplayed. ${ }^{38}$

But if urgency was one ethos animating the infrastructuring of HSNP, it was not the only one. Throughout my fieldwork, the aid workers would invoke an ethical regime of self-conscious humanitarianism. As mentioned above, shopkeepers were castigated for violating "the rights component" of HSNP. Biometric scanners were adopted to meet beneficiary "dignity" and errors were fixed "on humanitarian grounds." While not carefully theorized or explicated, these discourses provided an ethical repertoire that shaped and was shaped by the act of infrastructuring. When technology proved recalcitrant or shopkeepers wayward, these forms of reasoning justified responses that did, ultimately, enable the delivery of cash on a large scale.

The HSNP, however, also had aspirations for more substantive forms of citizenship. One interesting plan that was taking shape in early 2013 was to fund "one-stop human rights shops" where instead of just collecting complaints and grievances about the program, HSNP infrastructure would be used to advocate on behalf of a broader range of rights violations in places like Turkana. ${ }^{39}$ This, of course, would be a high order but accorded with aspirations to leverage the seeming success of cash transfers for more substantive initiatives, including ongoing plans to unify and institutionalize the five different cash transfers into a fledgling state-based

\footnotetext{
38 On the humanitarian denigration of privacy, see Hosein and Nyst (2013). In Kenya, where the state is rapidly expanding its surveillance apparatus, this is even more concerning and how it partakes in the sovereign power to take life is an urgent question. Within the social protection sector, there were signs of some shift toward more privacy protection (see CaLP 2013).

39 On the weaknesses of such an approach, see Englund (2006).
} 
welfare program (though largely donor funded). While the road to such a future would be long, the aspirations were already shaping infrastructural design in the present: through the aforementioned plan to biometrically enroll everyone in the arid and semi-arid lands, but also to combine these into a "single registry" with other cash transfers in Kenya, perhaps creating the administrative infrastructure of a welfare state (cf. Szreter and Breckenridge 2012).

What this suggests is that in contrast to the "advanced liberal societies" (Rabinow and Rose 2006) more commonly analyzed, the global South may be the site of emergent biopolitical citizenships (Ferguson 2015). In contrast to the thanatopolitical analysis of Agamben, this case suggests the value of being open to affirmative forms of biopolitics, such as those associated with Roberto Esposito (2011; 2012). As scholars attuned to materiality have noted, discussions of biopolitics too rarely take into account techne, "without which the "becoming political" of our biological existence can hardly be conceived. Divorced from the things that constitute human life as such, biopolitics instead comes to be cast in ahistorical and metaphysical terms" (Braun and Whatmore 2010: xi; see also Campbell 2011).

Despite all this, much of the actually existing infrastructure of humanitarianism in northern Kenya remained special-purpose and exclusive. SUVs sped past pastoral communities; biometric scanners remained the property of the program (and would hardly be useful otherwise). The aid workers I observed were, in large part, interested in making the technology disappear and fade into the background. They did not want their infrastructure to be open to contestation, but rather simply to work. What results is opportunistic, delicate, and unwieldy, but also clever, largely functional, and novel. A focus on solving narrowly defined problems (i.e. a paucity of cash) has contributed to the "minimalist biopolitics" that Redfield (2012) says characterize humanitarianism. Fostering life, yes, but in a precarious, securitized, and thin manner. 


\section{Acknowledgments}

I gratefully acknowledge the assistance and time of my interlocutors in Kenya. Versions of this paper benefited from comments by Jeremy Seekings, Paul Edwards, Aaron Martin, and three anonymous reviewers. It was made possible by support from Privacy International, the Institute for Money, Technology \& Financial Inclusion at UG Irvine, and a Fulbright Fellowship. 


\section{References}

Ajana, B, 2013, Governing through Biometrics: The Biopolitics of Identity (Palgrave MacMillan, London)

Akrich M, 1992, "The De-Scription of Technical Objects", in Eds W.E. Bijker and J. Law Shaping Technology/Building Society: Studies in Sociotechnical Change (Cambridge: MIT Press)

Augé M. 2009, Non-Places: An Introduction to Supermodernity (Verso, London)

Bennet, J, 2010, "Thing-Power", In B. Braun and S. Whatmore (Ed.) Political Matter: Technoscience, Democracy, and Public Life (University of Minnesota Press, Minneapolis)

Bowker G.C. 1994, Science on the Run: Information Management and Industrial Geophysics at Schlumberger; 1920-1940 (The MIT Press, Cambridge, MA)

Braun, B, and Whatmore, S, 2010, Political Matter: Technoscience, Democracy and Public Life (University of Minnesota Press, Minneapolis)

Callon, M, 1986, "Some elements of a sociology of translation: domestication of the scallops and the fisherman of St Brieuc Bay", In J. Law (Ed.) Power, Action, and Belief: A New Sociology of Knowledge? (Routledge, London)

Callon, M and Latour, B, 1981, "Unscrewing the Big Leviathan; or How Actors macro-structure reality and how sociologists help them to do so", In K. Knorr and A. Cicourel (Eds.) Advances in Social Theory and Methodology (Routledge, London)

Callon M, Millo Y, and Muniesa, F. 2007, Market Devices. London: Wiley-Blackwell.

CaLP. 2013. Protecting Beneficary Privacy: Principles and operational standards for the secure use of personal data in cash and e-transfer programmes. (The Cash Learning Project, Oxford)

Campbell, T, 201 1, Improper Life: Technology E Biopolitics from Heidegger to Agamben (University of Minnesota Press, Minneapolis)

Collier S J, 2011, Post-Soviet social: neoliberalism, social modernity, biopolitics (Princeton University Press, Princeton, $\mathrm{NJ}$ )

Daston L, Galison P, 2007, Objectivity. (Zone Books, Cambridge, MA)

Donovan K, 2015. "The Biometric Imaginary: Bureaucratic Technopolitics in Post-Apartheid Welfare" Journal of Southern African Studies 41(4).

Dourish P, Bell G, 2007, "The infrastructure of experience and the experience of infrastructure: meaning and structure in everyday encounters with space" Environment and Planning B Planning and Design, 34(3), 414.

Dreze J, Sen A, 1991, Hunger and Public Action. Oxford: Oxford UP.

Duffield, M, 2001, Global governance and the new wars (Zed Books, London)

Edwards PN, 2003, "Infrastructure and modernity: Force, time, and social organization in the history of sociotechnical systems", In P. Brey, A. Rip and A. Feenberg (Eds.) Technology \&® Modernity: The Empirical Turn (MIT Press, Cambridge, MA)

Edwards PN, 2010, A Vast Machine: Computer Models, Climate Data, and the Politics of Global Warming (MIT Press, Cambridge, MA)

Edwards PN, Jackson SJ, Bowker GC, Knobel CP, 2007, Understanding Infrastructure: Dynamics, Tensions, and Design. Available at: pne.people.si.umich.edu/PDF/ui.pdf

Edwards PN, Bowker GC, Jackson SJ, Williams R. 2009, Introduction: An Agenda for Infrastructure Studies. Fournal of the Association for Information Systems 10 364-374

Elyachar J, 2012a, "Before (and After) Neoliberalism: Tacit Knowledge, Secrets of the Trade, and the Public Sector in Egypt" Cultural Anthropology 27(1) 76-96

Elyachar J, 2012b, "Next Practices: Knowledge, Infrastructure, and Public Goods at the Bottom of the Pyramid" Public Culture 24(1) 109-129 
Englund, H, 2006, Prisoners of Freedom: Human Rights and the African Poor (University of California Press, Berkeley)

Esposito, R, 2011, Immunitas: The Protection and Negation of Life (Polity, London)

Esposito, R, 2012, Terms of the Political: Community, Immunity, Biopolitics (Fordham University Press, New York)

Fassin D, 2007a, "Humanitarianism: a nongovernmental government", In Ed. M. Feher Nongovernmental Politics (Zone Books, Cambridge, MA)

Fassin, D, 2007b, "Humanitarianism as a Politics of Life", Public Culture 19(3), 499-520

Fassin, D, 2009, "Another Politics of Life is Possible", Theory, Culture E Society 26(44), 44-60

Ferguson J, 2010, “The uses of neoliberalism” Antipode 41 (s1) 166-184

Ferguson J, 2013, "Declarations of dependence: labour, personhood, and welfare in southern Africa" Journal of the Royal Anthropological Institute 19(2),223-242

Ferguson, J, 2015, Give a Man a Fish: Reflections on the New Politics of Distribution (Duke University Press, Durham, NC)

Ferguson J, and Gupta A, 2002, "Spatializing States: Toward an Ethnography of Neoliberal Governmentality" American Ethnologist 29(4) 981-1002

Foucault, M, 2009, Security, Territory, Population: Lectures at the College de France, 1977-1978 (Picador, New York)

Garcia M, and Moore CMT, 2012, The Cash Dividend: The Rise of Cash Transfers in Sub-Saharan Africa (World Bank, Washington, D.C.)

GoK 2012, Kenya Social Protection Sector Review. Nairobi. Available at: www.vision2030.go.ke/cms/vds/Kenya_Social_Protection_Review_Final.pdf

Graham S, and Marvin S. 2001, Splintering Urbanism: Networked Infrastructures, Technological Mobilities and the Urban Condition (Routledge, London)

Guldi J, 2012, Roads to Power: Britain Invents the Infrastructure State (Harvard University Press, Cambridge, MA)

Guyer J, 2004, Marginal Gains: Monetary Transactions in Atlantic Africa (University of Chicago Press, Chicago)

Hanlon J, Barrientos A, Hulme D, 2010, Fust give money to the poor: The development revolution from the global South (Kumarian Press)

Hosein G, Nyst C, 2013, Aiding Surveillance: An exploration of how development and humanitarian aid initiatives are enabling surveillance in developing countries (Privacy International, London)

Hughes T, 1993, Networks of Power: Electrification in Western Society, 1880-1930 (JHU Press, Baltimore)

Jackson SJ, 2014, "Rethinking Repair", In T. Gillespie, P. Boczkowski, and K. Foot (eds). Media Technologies: Essays on Communication, Materiality and Society (MIT Press, Cambridge, MA)

Jensen CB, and Wintheriek BR, 2013, Monitoring Movements in Development Aid: Recursive Partnerships and Infrastructures (MIT Press, Cambridge, MA)

Larkin B, 2004, "Degraded Images, Distorted Sounds: Nigerian Video and the Infrastructure of Piracy" Public Culture 16(2) 289-314

Larkin B, 2008, Signal and noise: media, infrastructure, and urban culture in Nigeria (Duke University Press, Durham, NG)

Larkin B, 2013, "The Politics and Poetics of Infrastructure" Annual Review of Anthropology 42 32743

Latour, B. 1994, “On Technical Mediation-Philosophy, Sociology, Genealogy" Common Knowledge $\mathbf{3}(2)$ 29-64 
Latour B, 1999, "When Things Strike Back: A Possible Contribution of Science Studies to the Social Sciences" British Fournal of Sociology 51(1) 105-123

Lipsky M, 1980, Street-Level Bureaucracy: Dilemmas of the Individual in Public Services (Russell Sage Foundation, New York)

Lyon D, (Ed.). 2003, Surveillance as Social Sorting: Privacy, Risk and Automated Discrimination (Routledge, London)

MacKenzie D, 2009, Material Markets: How Economic Agents are Constructed (Oxford UP, Oxford)

Magnet S, 2011, When Biometrics Fail: Race, Gender, and Technology of Identity (Duke UP, Durham, $\mathrm{NG}$ )

Mas I, 2012, My PIN is 4321. CGAP Blog. Available at: www.cgap.org/blog/my-pin-4321

Maurer B, 2012a, "Mobile Money: Communication, Consumption and Change in the Payments Space" Fournal of Development Studies $\mathbf{4 8}$ (5) 589-604

Maurer B, 2012b, "Payment: forms and functions of value transfer in contemporary society" Cambridge Anthropology 30(2) 15-35

Maurer B, Nelms TC, Rea SC, 2013, “Bridges to cash': channeling agency in mobile money" Fournal of the Royal Anthropological Institute 19(1) 52-74

McCabe, J T, 2004, Cattle Bring Us To Our Enemies: Turkana Ecology, Politics, and Raiding in a Disequilibrium System (University of Michigan Press, Ann Arbor)

Mosse D, 2004, Cultivating Development: An Ethnography of Aid Policy and Practice (Pluto Press, London)

Ong, A, 2006, "Mutations in Citizenship", Theory, Culture E Society 23(2-3), 499-505

Pipek V, Wulf V, 2009, "Infrastructuring: Towards an Integrated Perspective on Design and Use of Information Technology" Fournal of the Association of Information Systems 10(5) 306-332

Rabinow, P, and Rose, N, 2006, "Biopower Today", BioSocieties 1, 195-217

Redfield P, 2012, "Bioexpectations: Life Technologies as Humanitarian Goods" Public Culture 24(1) 157-184

Redfield P, 2013, Life in Crisis: The Ethical fourney of Doctors without Borders (UC Press, Berkeley)

Rottenburg R, 2009, Far-Fetched Facts: A Parable of Development Aid-Inside Technology (The MIT Press, Cambridge, MA)

Roy A, 2010, Poverty Capital: Microfinance and the Making of Development. (Routledge, New York)

Samson M, van Nieker I, and Mac Quene K, 2011, Designing and Implementing Social Transfer Programmes $2^{\text {nd }}$ Edition (EPRI, Cape Town)

Seekings J, 2008, "Deserving individuals and groups: the post-apartheid state's justification of the shape of South Africa's system of social assistance" Transformation 68.

Setel P, MacFarlane S, Szreter S, Mikkelsen L, Jha P, Stour S, AbouZahr C, 2007, "A scandal of invisibility: making everyone count by counting everyone" The Lancet 37(9598) 1569-1577

Smirl L, and Lister B, 2010, Drive-By Development: Thinking Through the Sports Utility Vehicle in Humanitarian Assistance. Available at:

backdoorbroadcasting.net/2010/12/lisa-smirl-and-beth-lister-drive-by-developmentthinking-through-the-sports-utility-vehicle-in-humanitarian-assistance/

Star SL, 1999, "The ethnography of infrastructure" American behavioral scientist 43(3) 377-391

Suchman L, 2006, Human-Machine Reconfigurations: Plans and Situated Actions (Cambridge UP, Cambridge, UK)

Szreter S, and Breckenridge K, 2012, "Editor's Introduction: Recognition and Registration: The Infrastructure of Personhood in World History", In K. Breckenridge and S. Szreter (Eds.) Registration and Recognition: Documenting the Person in World History (Oxford UP, Oxford, UK) 
Takhteyev Y, 2012, Coding Places: Software Practice in a South American City (MIT Press, Cambridge, MA)

Ticktin, M, 201 1, Casualties of Care: Immigration and the Politics of Humanitarianism in France (University of California Press, Berkeley) 